\title{
Patient and Healthcare Professional Perspectives from ESMO 2021 on Bladder and Kidney Cancer: A Podcast
}

\author{
Alex Filicevas · Thomas B. Powles
}

Received: November 8, 2021 / Accepted: January 18, 2022 / Published online: March 3, 2022

(c) The Author(s) 2022

\begin{abstract}
In this plain language podcast, highlights from the European Society for Medical Oncology (ESMO) Congress 2021 are discussed from the perspective of both a patient and a healthcare professional. The patient advocacy track at the congress was co-developed with patients, and was integrated into the overall programme. It included four sessions on the financial impact of cancer, treatments that use the body's immune system to fight cancer, technology, and rare cancers. This comes at a time when there is an increasing focus on the value of realworld data (data from a real-life setting, rather than in a clinical trial) and a more active role for patients and patient organisations as partners in research. Challenges and opportunities arising during the COVID-19 pandemic were also discussed, including logistical complexities in
\end{abstract}

Supplementary Information The online version contains supplementary material available at https:// doi.org/10.1007/s40487-022-00185-5.

A. Filicevas $(\square)$

World Bladder Cancer Patient Coalition, Brussels, Belgium

e-mail: alex.filicevas@worldbladdercancer.org

T. B. Powles

Barts Experimental Cancer Medicine Centre, Barts

Cancer Institute, QueenMary University of London, London, UK

e-mail: thomas.powles1@nhs.net healthcare and consequent uncertainty for patients in accessing care, and opportunities including increased use of telemedicine and broader participation offered by virtual/on-site hybrid congress formats, as used in ESMO 2021. Data discussed on combination treatments for patients with bladder cancer suggest an improved chance of remission for patients intolerant or resistant to existing treatment. Some of the data from studies in kidney cancer also suggest that treatment breaks or longer periods between treatment can improve quality of life and reduce treatment costs, without reducing treatment effectiveness. Although data on bladder and kidney cancer studies were seen to be promising, the authors recognise the time it takes for such findings to reach clinical practice, and the importance of managing expectations in the patient community. The authors conclude their discussion by reflecting on key challenges and opportunities moving forward, including restoring and improving care and efficiency of cancer services, and working together with patient advocates and advocacy organisations as essential partners in achieving this.

Keywords: Bladder cancer; COVID-19; ESMO Congress; Kidney cancer; Patient involvement; Real-world evidence 


\section{Key Summary Points}

The patient advocacy track at the 2021 ESMO congress was co-developed with patients and was integrated into the overall programme.

The increased prominence of the patient voice in the congress programme, plenary sessions and wider discussions parallels the evolving relationship between patient organisations and the medical research community, where patients are increasingly involved as partners in clinical trial design and development.

The COVID-19 pandemic has presented new challenges such as uncertainty in accessing care and delayed diagnoses, but also new opportunities such as increased use of telemedicine, increased prominence of virtual/on-site hybrid congresses and the ability to open clinical trials more quickly.

Data from studies in bladder and kidney cancer offer new hope for patients; however, expectations in the patient community must be managed, accounting for the time it takes for research data to influence clinical practice.

Key challenges moving forward include restoring and improving care and efficiency of cancer services; patient advocates and advocacy organisations are essential partners in achieving this.

\section{DIGITAL FEATURES}

This article is published with digital features, including the podcast audio file, to facilitate understanding of the article. To view digital features for this article, go to https://doi.org/10. 6084/m9.figshare. 18414638

\section{PODCAST TRANSCRIPT}

Speaker 1: Hello, and welcome to this Adis Rapid+ podcast series. Today's podcast will focus on the European Society for Medical Oncology 2021 Congress, or ESMO for short. This podcast is aimed at everyone interested in the ESMO Congress and the latest research in genitourinary cancers. You don't need to be an expert, as the discussions will be in plain language with explanations given for any technical terms. Speaking today is Alex Filicevas, Executive Director of the World Bladder Cancer Patient Coalition, and Professor Tom Powles, Professor of Genitourinary Oncology at the Barts Cancer Centre in the UK. Although data from a number of studies in other genitourinary cancers (such as prostate cancer) were released at ESMO, the focus of this podcast will be bladder and kidney cancer. The views and opinions expressed in this podcast are solely those of the authors and do not necessarily represent those of ESMO or any of its affiliates. This podcast was sponsored by Pfizer. The journal's Rapid Service Fee was funded by Pfizer. No funding was provided for the authoring of this publication. The authors received no honoraria related to the development of this publication. Medical writing support was provided by Sarah McSorley, MSc, Simon Stones, $\mathrm{PhD}$, and Susan Tan, PhD, of Envision Pharma Group, and was funded by Pfizer.

Tom Powles: Hi, I'm Tom Powles. I'm a professor of oncology at Barts Cancer Centre in London and I've got an interest in drug development in urology cancer. Alex, do you want to introduce yourself as well?

Alex Filicevas: Yes, my name is Alex Filicevas and I'm the Executive Director of the World Bladder Cancer Patient Coalition, which is an international umbrella organisation uniting bladder cancer patient groups in different countries around the world.

Tom: Alex, it's great we've got here together today. We're going to talk about a series of things that you know a huge amount about and I'm going to sort of meander my way through if I may. The first is, we're going to talk a lot about patient involvement at ESMO. I can see patient 
involvement is becoming more prominent. I think everyone feels it's really important. We're going to talk about how it's becoming more prominent and also we're going to talk about the patient voice in research. I'm involved in some steering committees and people are talking to me more and more about how we get patients more integrated. I rarely go to an ethics committee without them asking how the patient is involved. And we're going to also then go on to some of the latest data on bladder and kidney cancer, which I think is cool, and we're going to talk a little bit about the potential impact of some of this research. We're not going to talk too much about prostate cancer, but we'll give sort of a few top-liners on that as well.

Alex: If we look at ESMO, and I think today we're looking at ESMO more kind of reflecting back-it's been a while since it took place-and also looking forward, you know, what it means in research and also patient involvement. And I think, you know, ESMO 2021 has been the second ESMO that we had during the pandemic, right? It was different, but it was great to see that they were able still to enable patients to participate, patient advocates to be exposed to the latest scientific research that we have presented at ESMO, and also providing patients with a platform at least where they connect with others, with each other, but also with healthcare professionals like yourself as well. And I think the virtual/on-site hybrid congress format that we have seen this year, and I think we see more of it in different congresses as well, has enabled patients and patient advocates to participate much more wider, reducing those geographical barriers as well. So I think hybrid format might actually be a more open way forward for when it comes to patient participation in congresses.

Tom: A couple of questions. So the first is: Some meetings, the patients are having their own separate tracks within the congress, other meetings patients are taking part by asking questions. It's not that frequent to have patients engaged formally in some of the main sort of plenary sessions, for example. What's actually going on right now? Are there separate tracks for patients or is there integration? And what's going to happen in the future in your opinion?
Alex: Well, I think 2019 feels a bit like it was a lifetime away now and that was the last time I attended ESMO. I think we had about 350 plus patient advocates there and it's a very international group of patients. And I think patient voices are incorporated at ESMO through the Patient Advocates Working Group as well, and I think they have very active role in shaping their programme at ESMO Congress. We have patient advocacy tracks which go in parallel to the scientific sessions which enable patients to learn a little bit more information that relates to patient advocacy or maybe more broader generic oncology kind of scientific information. This year, the track included some interesting sessions on financial toxicity, immuno-oncology, technology and rare cancers. When we had these in person, we had more sessions; this year there were four in total. But I also see the patient voice being much more prominent in more plenary sessions and in wider discussions, not just limited to our patient advocacy track and patient community.

Tom: What do you think about how the online revolution during the last two years has influenced the way that patient advocates are able to integrate with the programme, and what does the future look like?

Alex: Well, I think the programme has enabled more wider participation, I suppose from patient advocacy community in Europe but as well from beyond. It allows us to also connect with a programme at a different time, so those not necessarily being able to participate during the live sessions, we have access and ability to join these later on. I think, yes, as I mentioned a bit earlier, moving forward I see this hybrid format being much more prominent because it is more accessible to a patient advocacy community and it's much more broader distributed. And I think also working together with our patient advocates who are not able to travel may be able to bring in different perspectives and learning more about the information that is very relevant to our patient communities in different countries.

Tom: What is the structure of this advocacy track within ESMO that's ongoing at the moment? What does the structure look like? Is 
it formal presentations? Is it group discussions? What does that look like?

Alex: So, we have the patient track, and I say we have it as a patient advocacy community I am not affiliated with ESMO in any way, but during the patient advocacy tracks it's a bit of presentation sessions and a Q\&A discussion. It has been a similar format in the past as well when we had opportunity to meet during these events in person. But what was more valuable, I suppose, when we look back at-you know, where we were when we were able to meet in person-was ability to then follow up and network with other patient advocates and healthcare professionals and discuss those learnings that we have seen on stage, then off stage and during our networking events, etc. The presentations that we have seen this year at ESMO and in previous cases as well, it comes from both the community itself, so showcasing some projects that our community undertakes in patient advocacy and also some wonderful research that has been going on, but also from healthcare professionals and updates from the scientific research that is also being shared at ESMO.

So patient voice has been very prominent not just in ESMO discussions overall in the programme but also in research, and when it comes to research we have seen also evolving relationships between patient organisations, researchers and industry as well. And it comes at a time where I think more within and outside our communities and more individuals are not just recognising that importance of patient voice that our patient advocates community has been raising for quite some time. So not just the importance of the voice in the research but also we are all trying to make the steps forward for a more inclusive research culture. I think it is important to highlight that the patient voice should be the guiding voice when it comes to research design, so it's not necessarily that the patient community should only be helpful at a time when we need to recruit for clinical trials but really designing ... meaningfully involving patients in the design of the research, and carrying that research out with them rather than for them. I think congresses have been great, ESMO included, in bringing that data forward and showcasing where this research, where patients have had a greater voice, and we do have this different data that is presented at the congresses, right? Where we have real-world evidence versus trial data and trying to bring that understanding as well into our patient community and sort of that scientific education to them, and explaining the real-world evidence which explores the data from larger groups of populations, right? To which our patient groups often have access to as well. So they are great partners in that sense. And versus the difference as well that it is between that and conventional clinical trials. And in my view, and it would be interesting to hear Tom, as well, your perspective: how do you view this different data and whether do we see it as complementary to each other or one is much more valuable than the other? Maybe you could just give us a hint on your perspective on this.

Tom: We're going to have to integrate this and we're going to have to do it together. You know, something simple like patient-reported outcomes, I'm not sure we've got that right. We did a study called PISCES in kidney cancer a while ago, where we asked patients if they'd prefer pazopanib or sunitinib, a really black and white... you know, that was the primary endpoint of the trial. I think we need to move towards that. I also think there are opportunities where we could do it better. So we could use apps and we could use wearable devices to get real-time information from patients. But unless we ask patients what's relevant to them, we'll never really know what's important. Is haematuria a worse symptom than lethargy associated with chemotherapy? Well, these sorts of questions. And I think we need to integrate patients into that process and of course we need to be, I think, more inclusive in when we're taking part in designing these trials to make sure that patients are included in that, because sometimes we find recruitment goes much slower than we expect and perhaps that might have been predictable if we were slightly more inclusive. So I'd like to see this process more inclusive and, you know, should we be having healthcare providers, but also, the wider group involved in some of the more academic formal parts of the meetings? So, for example, the 
chairing of the sessions or some of the patient perspectives or even some of the discussion.

Alex: Absolutely. And I think, you know, educating patients and patient advocates about the role of different types of data and their role as patient organisations as well in collecting data and how that is used also in broader discussions both scientifically and I would say policy as well, on the policy side of things. And having that step, I suppose, from patient advocacy track for patient representatives into the main sessions when we have these discussions at ESMO, other leading congresses, is important.

Tom: I think there's huge appetite for that. You know, I think you can see ESMO and other organisations really wanting to pursue patient representatives being... having a role, a big role, in the way the meetings are run.

Alex: That's fantastic to hear and I think this is what, you know, our community wants to take those active roles as equal partner, not just a voice to make a comment, but really meaningfully get involved in this. You know, at the session as well we had a study presented from Prof Giles about a global patient survey from the kidney cancer patient community which shared some findings and I just wanted to highlight one point from it: that $41 \%$ of patients indicated that no one discussed cancer clinical trials with them. How do you feel about that? And I know that you are involved in quite a lot of research and how can we educate our communities both from patient side but also healthcare professionals as well to make sure that we have more discussions with patients about clinical trials as a treatment option.

Tom: Yeah, so there isn't a trial for every patient at every hospital with every scenario. We know only a minority, perhaps $1 \%$ of patients go into clinical trials. And discussing patient trials that don't exist or they can't take part in is quite a grey issue. It's like discussing treatments for patients they can't have; I'm not sure how helpful it is. So I think that wider access to trials is really important and I think that patient advocate groups and patient representative groups have an important role to play in the broadcasting of the availability of trials. It's something we're trying to pursue in the UK by having regular meetings with patient groups around the trials that are available because then they can be disseminated on social media and that process then means that there's a network for each individual cancer that carers and patients can go to, to look for trials. Because the reality is for the vast majority of patients who are not looked after in the tertiary referral, you know, the Institute Gustave Roussy or the Marsdens of this world, it's hard for those hospitals to open a trial for every patient, so communication's really important.

Alex: And in this role, I suppose for patient advocacy communities, so patient organisations like my own, the World Bladder Cancer Patient Coalition as well, it's important to work with the healthcare professionals, with the research institutes and industry to ensure that we are aware of these trials and then working on the ground with patient organisations, like you said, to educate our patient communities about it as well.

So we've just talked about patient voice in research and their experience in clinical trials as well, and the care, and there is no doubt the COVID-19 pandemic also had an impact on patients with bladder and kidney cancer. And also this has been not a, say, focus of a discussion, but it has featured at ESMO as well, and we have seen in our communities in bladder cancer but also in kidney cancer as well, the uncertainty that patients have experienced, especially since the very beginning of the pandemic. Their uncertainty in ability to access care and treatment and especially postponements in their care that have added that extended anxiety and, I must say, the patient organisations have stepped in a lot to provide that comfort and support where possible, and as much information as they could to these patients. And I think the reality of all these missed diagnoses or late diagnoses is catching up with us now and we probably will need to see some action on that front. But Tom, you know, in your practice, what changes have you seen during COVID? And perhaps there are some positive learners from the COVID-19 pandemic that could change how cancer care is delivered in the long term?

Tom: There's a short answer and a long answer to this question. It's been... I think it's 
been challenging for everybody in healthcare, but I don't think we've seen the end of this yet. I think the anxiety around the spread of the infection and the effects of the infection particularly within healthcare environments has made delivering healthcare very difficult, you know, doing a CT scan, doing an MRI scan, the simple things have become much more complicated. Admitting a patient to hospital, do you put him in the same bay (him or her) as someone who has been there for a week and half and was negative? And how do we test? And just the logistical complexities make hospitals much less efficient.

Of course, you've now got the... that's had a knock-on effect, resulting in a backlog of treating patients. We've also got many people who've left healthcare because it's not... it's been a more challenging environment to work in, speaking frankly. And so we are, in cancer, running into a difficult time and there will be challenges beyond the pandemic associated with this. One of the things that was positive around the pandemic is we showed we could do trials very quickly. We were opening trials within a week. We historically take 18 months to open trials. I think that's a very positive note and I think we need to pursue that more actively.

Alex: So speaking of research and clinical trials, ESMO is a fantastic platform where we learn about scientific advances in the research and get a taste of how the future of cancer care might be delivered. And so although it can be exciting and promising to discuss the releases at congresses like ESMO, I think we also need to consider the time it takes to reach clinical practice and also why it is important to manage expectations in the patient community because we do of course get excited when we see promising data in our field, bladder cancer or kidney cancer. Early access in some cases might be possible through clinical trials or compassionate use programmes as well. Some are more familiar in our community about these programmes. There was a lot of data presented in the key sessions we had in ESMO in bladder and renal cancer, and Tom, I know you were involved in one of the studies called NORSE and I remember watching your presentation at
ESMO, so I wonder if you could shed some light on this study and others presented as well at ESMO 2021?

Tom: Thank you, Alex. It was a collaboration of a number of different sites around the world, the NORSE trial. It looks at individuals who have advanced urothelial cancer. It's their first treatment for metastatic or advanced disease and it looked at those patients, in the tissue, in their cancer tissue, the biopsy that was taken, molecular analysis of that looked for a specific protein called FGFR. A drug called erdafitinib targets that protein FGFR and it was given alone or in combination with an immune drug called cetrelimab. And essentially what we showed in a relatively small cohort of patients is that combining drugs together-immune drugs and personalised drugs together-was associated with high response rates, $68 \%$ in this case, which I think was really provocative. Now, it's too small to change practice, but we saw a similar piece of work from a different group with a different combination, this was ephrinB4, the details aren't that important, it's an immune or angiogenic therapy but again, combined with immune therapy, higher than expected response rates.

So there are some really exciting combinations in the pipeline and in the short term they're unlikely to have a huge impact on patients, but in the medium term, and what I mean by the medium term is the three to five year term, I think urothelial cancer's going to really change and I think that there are different combinations, about four or five different combinations that we're looking at, which I think are going to be really exciting.

Alex: Thank you, Tom. And these results I think are important as well because they do offer a new hope for patients with advanced bladder cancer who have fewer treatment options available at the moment. So it's really exciting to see these new studies and as you said, looking ahead in the next few years. At the moment, patients, of course, can only receive these drugs by participating in a clinical trial; however, if these trials continue to go well, these drugs might be available soon to our patient communities around the world. And a third key study from this session compared two 
types of chemotherapy given before and after surgery for muscle-invasive bladder cancer. It was VESPER study, I believe. What were the key findings there, Tom?

Tom: VESPER study looked at different types of chemotherapy. We have lots of different types of chemotherapy, two key different types of chemotherapy around the time of surgery for bladder cancer and that is the cystectomy, the removal of the bladder, big surgery. We routinely give perioperative chemotherapy at that time. And actually what we showed was that one type of chemotherapy might be a slightly better, slightly more active than a different type of chemotherapy. The trial was an investigatorled study from France, not funded or paid for by the pharmaceutical industry but by the French charities, which I think is really important. And certainly patient representative groups have a massive role to play in those public funding systems, and I know in the UK they do indeed have an extremely important role, and we get practical trials like this that come out the other end, so the French group should be congratulated for that.

Alex, you were going to talk a little bit about some key quality-of-life studies. From kidney cancer, there were two studies. There was the PRISM study and the STAR study looking at intermittent therapy or spacing out therapy. What were your takes from that?

Alex: So the findings from these two studies presented at the proffered paper session on kidney cancer. So as you said, it was the STAR study and the PRISM study. And they were important because they highlighted and looked specifically at the ability to incorporate treatment breaks or to extend the time between the treatments for patients. This is really important because this can lead to improvements in quality of life for patients undergoing treatment and also reduce treatment costs in some cases whilst at the same time losing no reduction in treatment effectiveness itself to patients. These studies really looked at improving the quality of life for patients in this.

Tom: Alex, that's a really innovative idea. Again they were investigator-initiated trials but looking at established treatments and instead of saying "This is the new drug, this how we're going to use it," refining existing drugs to try and maximise outcomes and maximise tolerability. I think that's really important and people have been saying for a long time, you know, we need to be doing these broader patient-orientated type trials because it is important for patients to know whether or not if they're going on holiday they take a break from the treatment or whether they can space their treatment out, whether they have to have it all at the beginning. So I thought they were terrific questions.

This has been a brief overview of ESMO 21, and in fact, there was a huge amount more that was going on, of course. One of the key findings was the adjuvant KEYNOTE-564 trial, adjuvant pembrolizumab compared to placebo after surgery, and nephrectomy for clear cell kidney cancer, and this showed a $32 \%$ reduction in the risk of the disease coming back, a significant reduction in the chance of the kidney cancer returning, which was statistically significant, and that's practice-changing and is going through regulatory type approval. So the research that we talk about at these meetings can translate really quite quickly into patients being offered new therapies to try and improve outcomes.

So we talked a bit about some of the hypothetical work at the beginning, then some of the early-phase trials, then some of the patient-orientated logistical trials, timing of therapy, and then at the end of course practice-changing big randomised phase threes that were led by Toni Choueiri. So I think this has been really exciting and I'll maybe... What are your take-home messages, Alex? What would you take home from this?

Alex: Well, I would just really like to highlight the fact that ESMO Congress, and hopefully more congresses in the future, is a fantastic platform for patient advocates to learn and network. But Tom, I even learned in this discussion with you today about some of these studies and they provide us extreme value as patient organisations and patient advocates towards the support and information that we provide to patients and caregivers facing bladder cancer and kidney cancer and so on. And so these learnings are extremely valuable for our community and I think they should be a 
standard practice at all leading congresses at the same time as incorporating that patient voice in the plenary sessions and bringing it into the discussions. So it's really fantastic and I'm hoping that this continues in person as we move forward next year, fingers crossed, but as I've mentioned as well, I think that hybrid model has opened up access to research and understanding and networking for a patient community that hasn't been able to do so before.

Tom: I learned from just talking to you as well, around how we can change some of our focus to make it more practical and potentially more applicable for a wider audience for the future. We've each got to give an opportunity for the next year and challenge, and I think that the challenge clearly is to try and get the healthcare system running, functioning again. I think the opportunity now is to reorganise some of our healthcare pathways to make them more efficient, ranging from telemedicine on the one hand, to opening trials more quickly. What about you from your perspective, Alex?

Alex: Exactly in line with what you just said. I think the biggest challenge for us will be to restore cancer care services and making sure that we not only going back to what it is before but we improve on that, we improve our care and efficiency to cancer services. And the most important message I would like to leave us with is the role of patient advocates and patient advocacy organisations as essential partners in making sure that we do achieve that moving forward.

Tom: Essential partners. Super cool. Alex, it's been terrific talking to you. I've really enjoyed it. I hope we do this again soon. Thank you very much.

Alex: Thanks, Tom. It was a pleasure.

\section{ACKNOWLEDGEMENTS}

Funding. This podcast was sponsored by Pfizer. The journal's Rapid Service Fee was funded by Pfizer. No funding was provided for the authoring of this review. The authors received no honoraria related to the development of this publication.

Medical Writing Assistance. Medical writing support was provided by Sarah McSorley, MSc, Simon Stones, PhD, and Susan Tan, PhD, of Envision Pharma Group, and was funded by Pfizer.

Authorship. The authors meet the International Committee of Medical Journal Editors (ICMJE) criteria for authorship of this article, take responsibility for the integrity of the work as a whole, and have given their approval for this version to be published.

Author Contributions. All authors made substantial contributions to the manuscript concept/design, critically reviewed, and revised the manuscript drafts, and provided final approval of the manuscript and enhanced content as submitted.

Disclosures. Alex Filicevas is an employee of the World Bladder Cancer Patient Coalition, which receives funding from Astellas, AstraZeneca, Bristol Myers Squibb, Ipsen, Janssen, MSD, Merck KGaA, Pfizer, Roche, and Seattle Genetics.

Thomas B Powles is a consultant for Astellas, AstraZeneca, Bristol Myers Squibb, Eisai, Exelixis, Incyte,Ipsen, Johnson \& Johnson, Merck, Merck Serono, MSD, Novartis, Pfizer, Roche, and Seattle Genetics.

Compliance with Ethics Guidelines This article does not contain any studies with human participants or animals performed by any of theauthors.

Peer Review Please note, contrary to the journal's standard single-blind peer review process, as a podcast this article underwent review.

Open Access. This article is licensed under a Creative Commons Attribution-NonCommercial 4.0 International License, which permits any non-commercial use, sharing, adaptation, distribution and reproduction in any medium or format, as long as you give appropriate credit 
to the original author(s) and the source, provide a link to the Creative Commons licence, and indicate if changes were made. The images or other third party material in this article are included in the article's Creative Commons licence, unless indicated otherwise in a credit line to the material. If material is not included in the article's Creative Commons licence and your intended use is not permitted by statutory regulation or exceeds the permitted use, you will need to obtain permission directly from the copyright holder. To view a copy of this licence, visit http://creativecommons.org/licenses/by$\mathrm{nc} / 4.0 /$.

\section{APPENDIX}

\section{Patient and Healthcare Professional Perspectives from ESMO 2021 on Bladder and Kidney Cancer-Glossary}

\begin{tabular}{ll}
\hline Term & Definition \\
\hline Adjuvant therapy & $\begin{array}{c}\text { Additional cancer treatment given } \\
\text { after the initial treatment, such } \\
\text { as surgery, to lower the risk that } \\
\text { the cancer will come back. }\end{array}$ \\
Advanced cancer & $\begin{array}{l}\text { The cancer has spread from where } \\
\text { it first started to nearby tissue, } \\
\text { lymph nodes, or distant parts of } \\
\text { the body. } \\
\text { A person who supports, } \\
\text { recommends, defends, or pleads } \\
\text { advocate } \\
\text { Medicines that prevent or slow the } \\
\text { growth of cancer cells by } \\
\text { stopping a process in the body } \\
\text { called angiogenesis. Angiogenesis } \\
\text { is the growth of new blood } \\
\text { vessels that tumors need to grow. } \\
\text { The removal of cells or tissues } \\
\text { from the body for examination. }\end{array}$ \\
\hline
\end{tabular}

Cohort

Appendix continued

\begin{tabular}{|c|c|}
\hline Term & Definition \\
\hline Blinded study & $\begin{array}{l}\text { A type of research study in which } \\
\text { the patients (single-blinded) or } \\
\text { the patients and their doctors } \\
\text { (double-blinded) do not know } \\
\text { which treatment is being given. }\end{array}$ \\
\hline Clinical trial & $\begin{array}{l}\text { Research studies of treatments, } \\
\text { performed in volunteers } \\
\text { (participants), which are } \\
\text { intended to add to medical } \\
\text { knowledge. }\end{array}$ \\
\hline Cohort & $\begin{array}{l}\text { Several individuals who are } \\
\text { grouped together for the } \\
\text { purposes of a research study. }\end{array}$ \\
\hline CT scan & $\begin{array}{l}\text { A computed tomography (CT for } \\
\text { short) scan uses a computer } \\
\text { linked to an x-ray machine to } \\
\text { create detailed images of the } \\
\text { inside of the body. These } \\
\text { pictures can show the difference } \\
\text { between normal and diseased } \\
\text { tissue. }\end{array}$ \\
\hline Cystectomy & Surgery to remove the bladder. \\
\hline Early phase trials & $\begin{array}{l}\text { Clinical research studies that test } \\
\text { the safety, side effects, and best } \\
\text { dose of a new treatment in small } \\
\text { groups of people. }\end{array}$ \\
\hline ESMO & $\begin{array}{l}\text { The European Society for Medical } \\
\text { Oncology (ESMO for short) is a } \\
\text { professional organisation for } \\
\text { healthcare professionals and } \\
\text { researchers who care for people } \\
\text { with cancer. }\end{array}$ \\
\hline FGFR & $\begin{array}{l}\text { Fibroblast growth factor receptor } \\
\text { (FGFR for short) is a protein } \\
\text { that is involved in cell growth, } \\
\text { bone growth, the formation of } \\
\text { new blood vessels, and wound } \\
\text { healing. }\end{array}$ \\
\hline
\end{tabular}


Appendix continued

\begin{tabular}{|c|c|}
\hline Term & Definition \\
\hline Gustave Roussy & $\begin{array}{l}\text { A specialist cancer hospital in } \\
\text { Villejuif, France. }\end{array}$ \\
\hline Hematuria & Blood in the urine. \\
\hline Hypothetical & $\begin{array}{l}\text { Based on possible ideas or } \\
\text { situations rather than actual } \\
\text { (factual) ones. }\end{array}$ \\
\hline Immune therapy & $\begin{array}{l}\text { A type of treatment that uses the } \\
\text { body's own immune system to } \\
\text { treat certain types of cancer. }\end{array}$ \\
\hline Intermittent therapy & $\begin{array}{l}\text { Treatment that is taken at set } \\
\text { times with breaks in between. }\end{array}$ \\
\hline Investigator-led study & $\begin{array}{l}\text { Clinical research studies that are } \\
\text { not initiated and managed by a } \\
\text { pharmaceutical company (for } \\
\text { example, by a hospital). }\end{array}$ \\
\hline Lethargy & $\begin{array}{l}\text { A state of being drowsy and/or } \\
\text { lacking energy and mental } \\
\text { alertness. }\end{array}$ \\
\hline Marsden & $\begin{array}{l}\text { The Royal Marsden Hospital is a } \\
\text { specialist cancer hospital in } \\
\text { London, United Kingdom. }\end{array}$ \\
\hline Metastatic & $\begin{array}{l}\text { The cancer has spread from/ } \\
\text { beyond the first organ concerned } \\
\text { (such as the kidney) to other } \\
\text { parts of the body. }\end{array}$ \\
\hline MRI scan & $\begin{array}{l}\text { Magnetic resonance imaging (MRI } \\
\text { for short) is a type of scan that } \\
\text { uses radio waves and powerful } \\
\text { magnets linked to a computer to } \\
\text { produce detailed images of the } \\
\text { inside of the body. These } \\
\text { pictures can show the difference } \\
\text { between normal and diseased } \\
\text { tissue. }\end{array}$ \\
\hline $\begin{array}{l}\text { Muscle-invasive } \\
\text { bladder cancer }\end{array}$ & $\begin{array}{l}\text { The cancer has spread from where } \\
\text { it first started to the muscle wall } \\
\text { of the bladder. }\end{array}$ \\
\hline Nephrectomy & Surgery to remove a kidney. \\
\hline
\end{tabular}

Appendix continued

\begin{tabular}{ll}
\hline Term & Definition \\
\hline $\begin{array}{l}\text { Patient-reported } \\
\text { outcomes }\end{array}$ & $\begin{array}{c}\text { Reports from patients about their } \\
\text { own health, quality of life, or } \\
\text { ability to perform daily activities } \\
\text { associated with the health care } \\
\text { or treatment they receive. }\end{array}$
\end{tabular}

Perioperative therapy Treatment given around the time of surgery.

Phase 3 trial

A study that tests the safety and how well a new treatment works compared to a standard treatment. This is done in a larger group of people compared to early-phase trials.

Placebo

Primary endpoint

A placebo does not contain any active ingredients found in a study treatment. The placebo and study treatment(s) look alike.

The main result that is measured at the end of a study to see if a given treatment worked.

Quality of life

Aspects of an individual's sense of well-being and ability to carry out activities of daily living.

Randomised study

A research study in which the participants are divided by chance into separate groups that compare different treatments.

Real world evidence/

Real-world studies look at what real-world data happens to people in a real-life setting, rather than in a clinical trial.

Clinical trials are used to test and approve treatments but may not include representation of all the people with a specific disease, which is why real-world studies are needed. 
Appendix continued

\begin{tabular}{ll}
\hline Term & Definition \\
\hline Response rate & $\begin{array}{l}\text { Measurement of a patient's } \\
\text { response to treatment. }\end{array}$ \\
$\begin{array}{l}\text { Statistically } \\
\text { significant }\end{array}$ & $\begin{array}{l}\text { Describes a mathematical measure } \\
\text { of difference between groups. } \\
\text { This is meaningful in } \\
\text { understanding how well } \\
\text { treatments work. } \\
\text { The delivery of healthcare from a } \\
\text { distance using technology, such } \\
\text { as telephone and video } \\
\text { consultations. }\end{array}$ \\
& A specialist treatment centre. \\
\hline
\end{tabular}

Appendix continued

\begin{tabular}{ll}
\hline Term & Definition \\
\hline Urology & $\begin{array}{c}\text { A medical field which diagnoses } \\
\text { and treats diseases of the urinary } \\
\text { organs in females and the } \\
\text { urinary and reproductive organs } \\
\text { in males. }\end{array}$ \\
Cancer that begins in cells called \\
urothelial cells that line the \\
urethra, bladder, ureters, renal \\
pelvis, and some other organs.
\end{tabular}

